\title{
The Discussion on the Standards of Labor Remuneration
}

\author{
Yan-Hua LI ${ }^{1,2}$ \\ ${ }^{1}$ Harbin University of Commerce, School of Economics, Harbin, China, 150028 \\ ${ }^{2}$ East University of Heilongjiang, Department of Economics and Trade, Harbin, \\ China, 150066 \\ zwbee@163.com
}

\begin{abstract}
Keywords: Labor remuneration; the influence factors of labor remuneration; empirical analysis
\end{abstract}
\begin{abstract}
It is very important to study the influence factors of labor remuneration and raise it in China for the success of industrial upgrading and avoiding into the middle income trap. Based on the equilibrium theory of supply and demand in the labor market, we use the theories and models of econometric and software EViews 6.0 to analyze the influence factors of Chinese labor remuneration mainly from 1995 to 2014. The result shows that labor remuneration is highly related to per capita GDP, unemployment rate and gross enrollment ratio of higher school. The government should take the macroeconomic policy to increase the share of labor remuneration.
\end{abstract}

\section{Background}

The report of the 17th national congress for the first time put forward "raise the proportion of labor remuneration in primary distribution", and the 18th national congress report again proposes "raise the proportion of labor remuneration in primary distribution" five years later, this showed that low labor remuneration has become a difficult problem in primary distribution. Low labor remuneration in primary distribution of outstanding performance is in the following three aspects: one is the labor remuneration of GDP declined year by year. Labor remuneration in China accounted for the proportion of gross domestic product (GDP) in 2000 was $51.4 \%$, 39.74\% in 2007, and decreased $11.66 \%$. In 2007, the labor remuneration in United States accounted for 55.81\%, the UK is $54.5 \%$, the Swiss is $62.4 \%, 68.25 \%$ in South Africa .Second, the labor remuneration growth lags behind the economic growth. According to statistics, in recent 10 years, the growth of total amount of labor compensation is slower than the growth of GDP continuously. Additionally the labor compensation grew faster than GDP growth in 2002, the rest 8 years from 2000 to 2008, labor remuneration grew more slowly than GDP growth. From 2000 to 2008, labor compensation grew by an average of $13.3 \%, 1.6 \%$ slower than GDP. Third, in the relations of distribution among the government, enterprises and residents income distribution tilted to the government and enterprises. In 1995, in the first distribution of national income, the proportion of the government, enterprises and residents is 15:20:65, in 2007 the proportion of the evolution is 17:22:61. The income of government and enterprise has increased, the labor remuneration then has dipped by $4.74 \%$. The growth of workers wage can't keep up with the growth of enterprise and government fiscal revenue, the trend of "strong capital and weak labor" constantly strengthened. Low proportion of labor remuneration in primary distribution, which indicates that the working class didn't really share the achievements of the high economic growth, has caused the party and the government to attaché great importance and become the focus of academic circles.

\section{The Research Method and Content}

Labor remuneration is the price of labor, but the price is different from general merchandise, which is not naturally formed by the market, but objectively affected by a variety of economic and social factors. According to the common sense of economics, the adjustment of the labor remuneration may be related to the national economy level, financial income, living standard and labor productivity, may also be closely connected with economic factors such as consumer, government purchase, even with the employment, prices, exchange rates, interest rates, inflation, 
urbanization and mercerization. And these factors connect and restrict to each other. The article uses multiple regression analysis method to establish model affecting the proportion of labor remuneration, to determine the main influencing factors, and puts forward the corresponding policy recommendations according to the empirical conclusions targeted specification analysis.

\section{The Study of Labor Remuneration and Macro Factors}

\section{The Determination of Macro Factors}

Labor remuneration objectively is affected by a variety of economic and social factors according to check data and common sense of economics. The article states the factors such as the per capita gross domestic product (GDP), national finance income, the consumer price index, urban families on average annual consumer spending, rural family per capita annual consumer spending, inflation, unemployment, the gross enrollment ratio, the RMB exchange rate against the dollar, urban population ratio have influence on the labor remuneration.

\section{Data Analysis and Processing}

In this paper, data is from statistical yearbook and China's economy Web site from 1995 to 2014. Among the original data on-the-job worker average wage index and standard of the consumer price index is 100 according to last year. In order to unify the base year of data, we process for $1995=$ 100 in this paper.

\section{The Establishment of the Regression Model}

Multiple linear regression model is:

$$
\mathrm{y}=\mathrm{bo}+\mathrm{b} 1 \mathrm{x} 1+\mathrm{b} 2 \mathrm{x} 2+\ldots+\mathrm{b} 10 \times 10+\varepsilon
$$

In the model, b0, b1..., b10 is unknown parameters, $\varepsilon$ is random error. We assume that $\varepsilon \sim \mathrm{N}(0$, s?):

$$
\mathrm{E}(\mathrm{y})=\mathrm{bo}+\mathrm{b} 1 \mathrm{x} 1+\mathrm{b} 2 \mathrm{x} 2+\ldots+\mathrm{b} 10 \mathrm{x} 10
$$

This paper observes $\mathrm{Y}$ and $\mathrm{x} 1, \mathrm{x} 2, \ldots \mathrm{x} 10 \mathrm{n}$ times at the same time.

And this article selects the changes of factors from 1995 to 2014 as sample observation value, $n=$ 20 , so the sample observation value is: $\{\mathrm{Xi} 1 ; \mathrm{Xi} 2 ; \ldots, \mathrm{Xi10}, \mathrm{Yi}\} \mathrm{i}=(1,2, \ldots, \mathrm{n})$

They meet

$$
\begin{aligned}
& \text { yi=bo+b1Xi1+b2xi2+ }+\cdots+b 10 X i 10+\varepsilon_{i} ; \mathrm{i}=1, \quad 2, \cdots, \mathrm{n} \\
& \boldsymbol{\beta}=[\mathrm{bo}, \mathrm{b} 1 \ldots, \mathrm{bm}\} \mathrm{T}
\end{aligned}
$$

Using least square method to estimate $\boldsymbol{\beta}$, the squares sum of residual $\mathrm{Q}=\sum_{i=1}^{n}\left(\mathrm{y}_{\mathrm{i}}-\hat{\mathrm{y}}_{\mathrm{i}}\right)^{2}$ is minimal. Thus, the linear regression equation is:

$$
\hat{y}=\hat{b}_{0}+\hat{b}_{1} x_{1}+\cdots+\hat{b}_{10} x_{10}
$$

In the above formula, $\mathrm{x} 1$ shows per capita gross domestic product (GDP); $\mathrm{x} 2$ shows national finance income; $\mathrm{x} 3$ shows the consumer price index(CPI); $\mathrm{x} 4$ shows urban families in average annual consumer spending; $x 5$ shows rural households in the per capita annual consumer spending; $\mathrm{x} 6$ shows the rate of inflation; $\mathrm{x} 7$ shows the unemployment rate; $\mathrm{x} 8$ shows the gross enrollment ratio of colleges and universities; $\mathrm{x} 9$ shows the RMB exchange rate against the dollar, The RMB / $\$ 100 ; x 10$ shows ratio of urban population.

\section{Solution of the Model}

In order to research the constraint relationship between various factors, EViews6.0 software is used to obtain the correlation matrix of Xi1; Xi2; ..., Xi10 and Y. Get rid of poor correlation, results 
are shown in the table.

Table1 Dependent Test

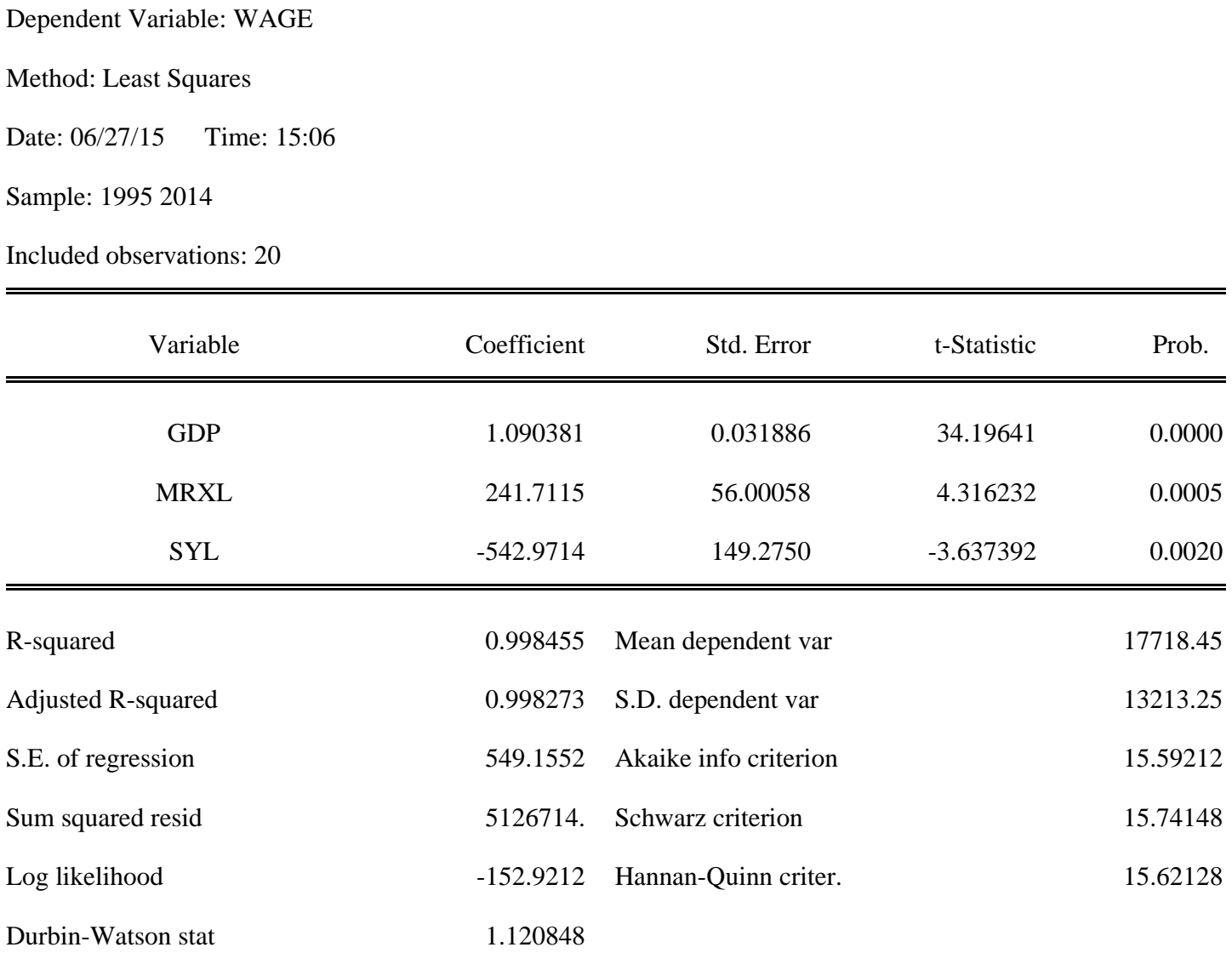

Procedure:

By analyzing the data listed in the table we can find that GDP, the gross enrollment ratio of institutions of higher learning and the unemployment rate are the biggest correlation with labor remuneration.

Multiple linear regression models of $\mathrm{Y}$ and the remaining variables are set up, the t statistics for each variable and goodness-of-fit coefficient R2 of the model is observed. The probability of T statistic is less than 0.05. R2 and the adjusted R2 were 0.998455 and 0.998273 , all were above 0.9, this shows that the established regression equation has a very good regression effect and significance. For the final regression model (t statistics for the corresponding coefficient is in the brackets)

$$
\begin{aligned}
& \mathrm{Y}=1.0904 \times 1-542.9714 \times 7+241.7115 \times 8 \\
& (34.19641) \quad(-3.637392)
\end{aligned}
$$

The heteroscedastic test is done in the model, the test results are in the following table:

Table 2 Heteroskedasticity Test

Heteroskedasticity Test: White

\begin{tabular}{lllr}
\hline \hline F-statistic & 0.671488 & Prob. F(6,13) & 0.6749 \\
Obs*R-squared & 4.731865 & Prob. Chi-Square(6) & 0.5786 \\
Scaled explained SS & 1.665002 & Prob. Chi-Square(6) & 0.9478 \\
\hline \hline
\end{tabular}


The probability of Obs*R-squared is greater than 0.05 , so the heteroscedastic problem does not exist in the model.

The correlation test is done in the model, the test results are in the following table,

Table3 Correlation Test

Test Equation:

Dependent Variable: RESID

Method: Least Squares

Date: 06/27/15 Time: 15:06

Sample: 19952014

Included observations: 20

Preamble missing value lagged residuals set to zero

\begin{tabular}{|c|c|c|c|c|}
\hline Variable & Coefficient & Std. Error & t-Statistic & Prob. \\
\hline GDP & 0.011306 & 0.030877 & 0.366171 & 0.0094 \\
\hline MRXL & -12.07581 & 53.55190 & -0.225497 & 0.0046 \\
\hline SYL & 12.85449 & 142.6392 & 0.090119 & 0.0094 \\
\hline RESID(-1) & 0.567793 & 0.273533 & 2.075775 & 0.0555 \\
\hline RESID(-2) & -0.337422 & 0.281564 & -1.198384 & 0.0094 \\
\hline R-squared & 0.223420 & Mean dependent var & & -24.90319 \\
\hline Adjusted R-squared & 0.016332 & S.D. dependent var & & 526.9269 \\
\hline S.E. of regression & 522.6061 & Akaike info criterion & & 15.56785 \\
\hline Sum squared resid & 4096758. & Schwarz criterion & & 15.81678 \\
\hline Log likelihood & -150.6785 & Hannan-Quinn criter. & & 15.61645 \\
\hline Durbin-Watson stat & 1.714381 & & & \\
\hline
\end{tabular}

The probability of GDP, MRXL, SYL is less than 0.05, this shows the three variables are without autocorrelation.

\section{Conclusion}

Through the regression equation, it can be found that labor remuneration is related to per capita GDP, unemployment rate and gross enrollment ratio of higher school. Among them, in the t statistic it is shown that Per capita GDP is the most significant influence on the labor remuneration; the average per capita GDP grows per 1, average wages would grow per 1.0904. It is stated overall economic level had a great influence on the average labor remuneration. 


\section{Countermeasures and Suggestions}

\section{Constantly Improve the Socialist Market Economic System}

Under the condition of incomplete market, primary distribution of national income not only is determined by the production factors and prices received in the market, there will be more rules or factors which affect income distribution. Unreasonable gap of income distribution will be created by monopoly market, labor market segmentation (labor can't flow freely in the market), information asymmetry in the capital market, the influence of non-economic factors on land market and so on. Therefore, we should keep improving the construction of the socialist market economy, building benign market mechanisms through a series of institutional arrangements and realizing the benign configuration, so as to realize a virtuous cycle. In deepening the reform of system of socialist market economy, there are some system constructions which have a greater influence on the primary distribution: the system of breaking up market monopoly, tessellating dealing system of the land market, the system of equal pay for equal work, the system of salary transparent, the minimum wage system, labor remuneration system, the system of priority to employment etc.

\section{Priority to Employment is the Key Point of Development Strategy}

International experience shows that the mode of so-called "distribution after development" in the practice of the Latin American countries is failure, and the east Asian mode of emphasizing the labor-intensive may be more suitable for China. Farmers and employees in state-owned enterprises in China are numerous; with the speeding up of transferring of the rural labor force to cities and re-employment difficulty of urban laid-off workers, so unemployment phenomenon is especially obvious, and the labor price have very competitive advantage in the world. Therefore, we should take priority to employment as one of the most important development strategy in the future, vigorously developing labor-intensive industries, especially the labor-intensive small and medium enterprises. The government should effort to create survival environment suitable for small and medium-sized enterprise, so as to create more jobs as much as possible and gain corresponding income.

\section{Both Efficiency and Equity Are In Primary Distribution}

Both efficiency and equity are in primary distribution, strengthening the regulation of irrational factors.

First, the normal growth mechanism and payment security system of enterprise worker's salary should be perfect. On the one hand, the mechanism of bargaining should be set up in the animal husbandry industry which has the lowest income, raising the wages to workers and breaking tax for businesses. On the other hand, the government should perfect guidance system of wage macro-control, giving full play to the adjustment of the wage guidelines, the wage guiding price in labor market and the artificial cost information.

Second, resource pricing mechanism must be improved. Resource cost ought to be accounted comprehensively, as far as possible to bring internal cost and external cost into the accounting scope. Circulation of resource products had better be reduced, preventing price to ascend monopoly income and insisting on distinguishing price mechanism between civil and commercial.

\section{Acknowledgements}

Received date: November 15, 2015

Fund Program: Humanities and social science project in Heilongjiang department of education"Urban comprehensive analysis and evaluation of the effect of convention and exhibition industry - as Harbin for example "(item number:12544071);Heilongjiang province philosophy social sciences planning project, ( item number:14C33); Harbin commercial university graduate student innovation project funding (item number: YJSCX2014-284HSD) "coordination countermeasures of tax financial policy to promote trade upgrade between Heilongjiang and Russian”. 


\section{Reference:}

[1] Guozhengmo, Hefei, mechanism perfect and institutional reconstruction of raising the proportion of labor remuneration in primary distribution, theory and reform (2011)

[2]Yinyanlin, Raising workers' compensation to improve the national income distribution, development and observation in China,(2011)

[3] Lizinai, econometrics (The third edition), Higher education press, (2009) 